\title{
Long-Term Memory Survives Nerve Injury and the Subsequent Regeneration Process
}

\author{
Ken Lukowiak, ${ }^{1,4}$ Zara Haque, ${ }^{2}$ Gaynor Spencer, ${ }^{1,3}$ Nishi Varshay, ${ }^{2}$ Susan Sangha, ${ }^{2}$ \\ and Naweed Syed ${ }^{2}$ \\ ${ }^{1}$ Department of Physiology and Biophysics, ${ }^{2}$ Department of Cell Biology and Anatomy, and Neuroscience and Respiratory Research Groups, \\ University of Calgary, Calgary, Alberta, Canada T2N 4N1.
}

\begin{abstract}
A three-neuron network (a central pattern generator [CPG]) is both sufficient and necessary to generate aerial respiratory behavior in the pond snail, Lymnaea stagnalis. Aerial respiratory behavior is abolished following a specific nerve crush that results in axotomy to one of the three CPG neurons, RPeD1. Functional regeneration of the crushed neurite occurs within 10 days, allowing aerial respiratory behavior to be restored. Functional regeneration does not occur if the connective is cut rather than crushed. In unaxotomized snails, aerial respiratory behavior can be operantly conditioned, and following memory consolidation, long-term memory (LTM) persists for at least 2 weeks. We used the Lymnaea model system to determine (1) If in naive animals axotomy and the subsequent regeneration result in a nervous system that is competent to mediate associative learning and LTM, and (2) if LTM survives RPeD1 axotomy and the subsequent regenerative process. We show here that (1) A regenerated nervous system is competent to mediate associative memory and LTM, and (2) LTM survives axotomy and the subsequent regenerative process.
\end{abstract}

A three-neuron central pattern generator (CPG) in Lymnaea, whose sufficiency and necessity has been shown, generates an easily recognizable and quantifiable behavior, aerial respiration (Syed et al. 1990, 1992; Syed and Winlow 1991). This behavior can be operantly conditioned, a form of associative learning, and depending on the training procedure used, the learning can be encoded into either intermediate-term and/or long-term nondeclarative memory (ITM/LTM) (i.e., "savings") (Lukowiak et al. 1996, 1998, 2000; Sangha et al. 2002; Smyth et al. 2002). Consistent with the hypothesis that nondeclarative memory is encoded within the same neuronal network that mediates the behavior (Milner et al. 1998), neural correlates of learning and memory have been found in the three-cell network, specifically in RPeD1, the neuron that initiates rhythmic activity in the CPG (Spencer et al. 1999, 2002). Moreover, we have recently demonstrated that the ablation of RPeD1's soma (i.e., removing its nucleus), but leaving its primary neurite functional (i.e., sufficient to enable aerial respiratory behavior to occur), creates a snail that has the capacity to associatively learn, form ITM but not form LTM (Scheibenstock et al. 2002).

Lymnaea possess a number of characteristics, which allow experiments to be performed, that would be very

\footnotetext{
${ }^{3}$ Present address: Department of Biology, Brock University, St. Catherine's, Ontario, Canada L2S 3A1

${ }^{4}$ Corresponding author.

E-MAIL lukowiak@ucalgary.ca; FAX 403-283-2700.

Article and publication are at http://www.learnmem.org/cgi/doi/ $10.1101 / \mathrm{lm} .48703$.
}

difficult or impossible in other preparations. The first of these is that Lymnaea are bimodal breathers, satisfying their respiratory needs via cutaneous and/or aerial respiration (Lukowiak et al. 1996). In the operant conditioning procedure, snails associatively learn not to perform aerial respiration in a hypoxic environment where that behavior should predominate. Thus, learning and remembering not to perform aerial respiration does not harm the snails. In fact, adult Lymnaea can be maintained for months in eumoxic experimental conditions where aerial respiration is prevented without any apparent deleterious effect (Hermann and Bulloch 1998; K. Lukowiak, unpubl. observations). Thus, procedures that preclude aerial respiratory behavior need not be lethal to the snail. A second characteristic of the Lymnaea model system is that Lymnaea neurons, including the respiratory CPG neurons, are capable of functional regeneration (i.e., neurite extension and appropriate synapse formation) both in vitro and in vivo (Syed et al. 1992; Haque 1999; Woodin et al. 1999). Haque (1999) found in freely behaving Lymnaea that following the crush of RPeD1's axon, one of the members of the three-neuron network, snails could not perform aerial respiration. However, $10 \mathrm{~d}$ later as a result of functional regeneration, as assessed both electrophysiologically and behaviorally, aerial respiratory behavior was restored.

All of these above-mentioned properties of the Lymnaea model system allow us to ask the following questions: (1) Is a regenerated central nervous system (CNS) competent to mediate both associative learning and LTM? (2) Does an already-established memory (i.e., LTM) survive axotomy

LEARNING \& MEMORY 10:44-54 @ 2003 by Cold Spring Harbor Laboratory Press ISSN1072-0502/03 \$5.00

$$
\begin{array}{lllllllllllllll} 
& E & A & R & N & I & N & G & \mathcal{Z} & M & E & M & O & R & Y \\
\text { www.learnmem.org } & & &
\end{array}
$$


and the subsequent functional regeneration processes? We attempted to answer these questions using two different experimental strategies to ascertain whether memory of associative learning was formed. We did this because there is always an inherent dilemma when testing for memory: whether to apply or not apply the reinforcing stimulus in the memory test (Wagner and Rescorla 1972). Thus, we tested for savings using (1) a procedural assessment where the reinforcing stimuli are delivered to the snail as in the training sessions, and (2) a memory test in which the reinforcing stimuli was not applied. Both procedures yielded similar results and thus we are confident Lymnaea are capable of forming long-lasting memories in a regenerated nervous system and that the cellular processes that constitute LTM are sufficiently robust to survive the processes that underlie neuronal regeneration. These questions and the answers to them are important not only because of their heuristic value but they may allow us in the future to specify where and how memory is encoded within single, identified neurons.

\section{RESULTS}

\section{Recovery of Aerial Respiratory Behavior Following Induced Trauma}

As respiratory rhythmogenesis in Lymnaea is initiated by RPeD1 activity (Syed et al. 1990), we hypothesized that crushing the right pleural-parietal connective, which contains RPeD1's primary neurite (Fig. 1), would result in the inability of the snail to perform aerial respiratory behavior. Moreover, we hypothesized that regeneration of the primary neurite would occur allowing the snail to again be able to perform aerial respiration. These data are presented in Figure 2. One day after the crush, none of the experimental animals tested ( 0 of 20 ) were able to perform aerial respiration (Fig. 2A). In five of these snails (randomly picked) Lucifer yellow (LY) fills of RPeD1 were made. In all cases, dye was not seen distal to the crush site. An example of one of these fills is shown (Fig. 2, top panel, left). Ten days following the connective crush, 12 of the remaining 15 snails tested on day 1 performed aerial respiration (Fig. 2). We randomly selected five of these snails from the 12 that exhibited aerial respiratory behavior and filled RPeD1 with LY. In all five cases, dye filled the primary neurite distal to the crush site into the parietal and visceral ganglia, and out to the periphery. An example of one of these fills is shown (Fig. 2, top panel, right). The remaining three snails when tested $3 \mathrm{~d}$ later were able to perform aerial respiration. Thus, following the connective crush, RPeD1's primary neurite functionally regenerates, allowing aerial respiration to occur. In snails $(\mathrm{N}=10)$ that had the right pleural-parietal connective cut rather than crushed, aerial respiratory behavior was never observed even though the snails remained alive for up to 3 weeks (data not plotted).

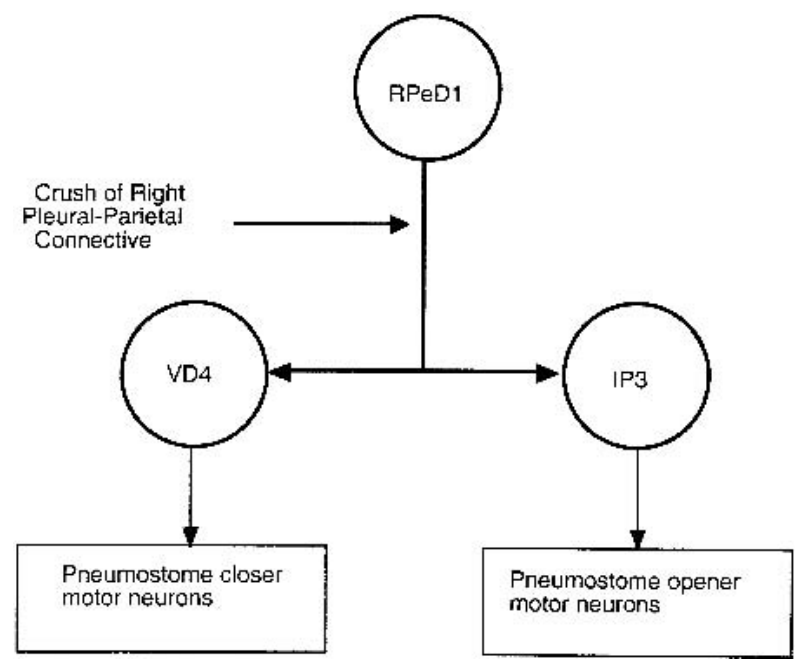

Figure 1 Schematic diagram of the right pleural-parietal connective crush in the experimental snails. The respiratory central pattern generator (CPG) in Lymnaea consists of three neurons, RPeD1, VD4, and IP3. RPeD1 initiates rhythmicity in this circuit by synaptic interactions with the other two CPG neurons, IP3 and VD4. RPeD1 is located in the right pedal ganglion. Neuron IP3 is located in the right parietal ganglion, and its activity activates pneumostome opener motor neurons. Thus, IP3 activity results in expiration. Neuron VD4 is located in the visceral ganglion and its output goes to the pneumostome closer motor neurons. Thus, VD4 activity controls inspiration. The axon (i.e., primary neurite) of RPeD1 courses through the right pleural-parietal connective. Crushing this connective interrupts the synaptic interactions necessary for the production of rhythmic activity needed for aerial respiratory activity. This crush does not interrupt the output from IP3 or VD4 to their respective follower motor neurons; nor does it interrupt the axons of the motor neurons to the periphery. With the functional regeneration of RPeD1's axon rhythmicity is restored and aerial respiratory behavior can be observed.

\section{Operant Conditioning of Aerial Respiratory Behavior Following Regeneration}

All together, six different cohorts of snails were tested. This enabled us to compare the learning abilities of snails that had functionally regenerated, were sham operated, or given a yoked control procedure.

The ability to associatively learn and form LTM in functionally regenerated snails was first tested by determining if the total breathing time in the hypoxic challenge was significantly different after training compared to the pretraining hypoxic challenge (Fig. 3). We observed aerial respiratory activity (total breathing time) in a group of 30 functionally regenerated snails ( $10 \mathrm{~d}$ postcrush). This gave us a pretraining index of their aerial respiratory behavior. This group of snails was then randomly divided up into the following three groups: (1) a naive group; (2) an operant conditioning (contingent) group; and (3) a yoked control group (yoked-procedure No. 2). Following the indicated training procedure for each cohort, a one-way repeated measures analysis of variance (ANOVA) was performed on these data testing both a within-groups factor (i.e., pre vs. post) and a

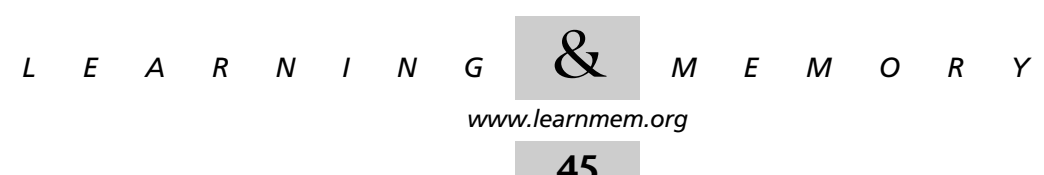



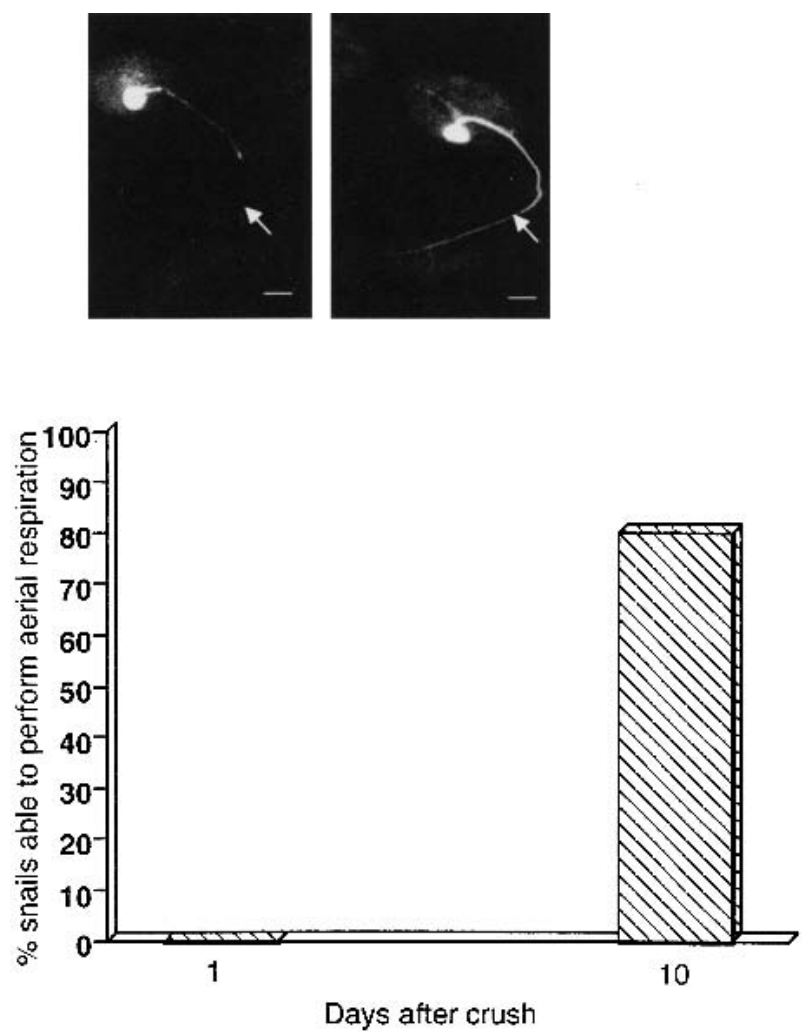

Figure 2 Aerial respiration after the right pleural-parietal connective crush. (A) A cohort of snails $(\mathrm{N}=20)$ had a nerve crush applied to the right pleural-parietal connective. They were placed in the hypoxic pond water on days 1 and 10 . One day after crush, 0 snails performed aerial respiration in a $1-\mathrm{h}$ observation period in hypoxic pond water. We randomly picked five snails for Lucifer yellow (LY) fills. On day 10 , however, 12 of the remaining 15 snails performed aerial respiration. Although not shown here, three days later the remaining three snails performed aerial respiration. In the sham group, all snails were able to perform aerial respiration on day 1 (data not shown). LY fills of RPeD1. In the left panel, a LY fill was made $1 \mathrm{~d}$ after the right pleural-parietal connective crush to show that RPeD1's axon was crushed. Notice that the LY does not reach the site of the crush, marked by the arrow, as the crushed neurite has pulled back from the site of injury. The right panel shows an RPeD1 fill $10 \mathrm{~d}$ after the crush; the arrow points to the approximate location of the crush. This snail exhibited aerial respiration before it was sacrificed for the LY fill. In the two panels, RPeD1 is $\sim 70 \mu \mathrm{M}$ in diameter. The scale bar is $70 \mu \mathrm{M}$ in each panel.

between-groups factor. The ANOVA $(\mathrm{F}[12,5]=7.687$, $P<0.0001)$ showed that there was a significant effect and thus we determined which (both within and between groups) sessions were significantly different from each other. We first determined the within-group differences between the pre- and postbreathing observation periods. In both the naive and yoked control groups, there was no significant difference (pre vs. post) in the total breathing time ( $P>0.05$ for each group). There was, however, a significant difference $(P<0.01)$ in the pre- vs. posttotal breathing time in the operant conditioned (contingent) group. That is, the total breathing time in the hypoxic challenge observation period following operant conditioning was significantly less than it was in the observation period before operant conditioning. We then performed between-group comparisons. There were no significant differences in the total breathing time in the pretraining observation period between the groups $(P>0.05$ for each respective comparison). There was also no significant difference between the total breathing time in the postobservation period between the naive and yoked control groups $(P>0.05)$. We found, however, that there was a significant difference in the total breathing time in the postobservation period between the contingent group and the naive group $(P<0.01)$ and between the contingent group and the yoked control group $(P<0.01)$.

It is apparent that only the operant training procedure (i.e., the contingent cohort) results in a significant change in the posttraining hypoxic challenge breathing behavior. We thus conclude that functionally regenerated snails have the capability to associatively learn and form LTM.

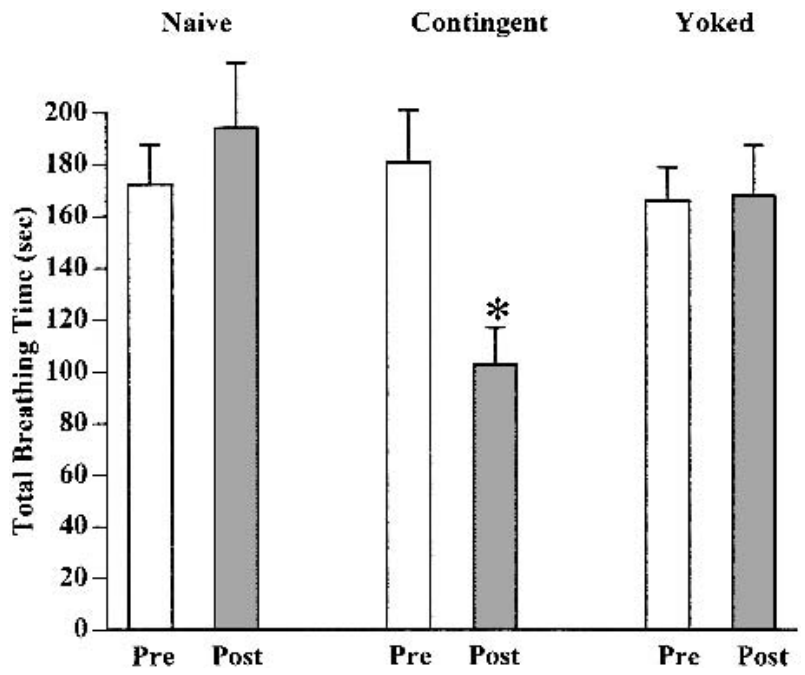

Figure 3 Learning and memory after functional regeneration. (A) A group of snails had their right pleural-parietal connective crushed and $10 \mathrm{~d}$ later all snails performed aerial respiration. All these snails were given a 30-min hypoxic challenge and their total breathing time tabulated (the pretraining test, Pre). They were then randomly assigned to one of three groups: naive, yoked, and contingent. The naive group was maintained in a eumoxic aquarium and $10 \mathrm{~d}$ later was again given the posttraining hypoxic challenge (Post). The contingent group received a tactile stimulus to their pneumostome every time they attempted to open their pneumostome. One week after the last training session, they received the posttraining hypoxic challenge. The yoked group received a tactile stimulus to their pneumostome, not when they opened their pneumostome, but when the snail that they were yoked to attempted to open its pneumostome. One week after the last yoked training session, these snails received the posttraining hypoxic challenge. There was no significant difference in the total breathing time (prevs. posthypoxic challenge) between the naive and yoked control groups. In the contingent (i.e., operant conditioning cohort), there was a significant decrease $\left(P<0.01,{ }^{*}\right)$ in total breathing time in the posttraining hypoxic challenge.

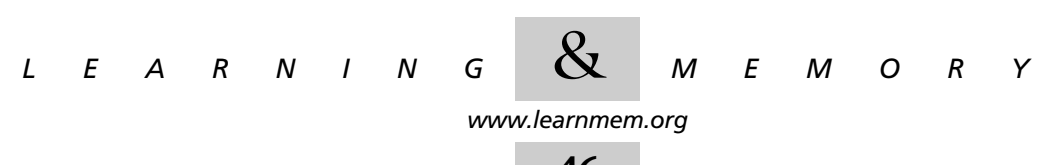


We next tested (Fig. 4) the remaining three cohorts of snails (10 sham control snails and 10 functionally regenerated snails received the yoked-procedure No. 1, and 10 functionally regenerated snails received the operant conditioning procedure) using a reinforcing test for savings to determine if associative learning could also be demonstrated 10 days postsurgery. Each cohort was also challenged with a change-of-context test (CC) session (Session 7 in Fig. 4) and a further standard test session (Session 8) $1 \mathrm{~h}$ following the $\mathrm{CC}$ session. On inspection, there appeared to be no differences in the learning curves or responses in the saving-test between the sham and the regenerated snails. We statistically confirmed this by using a single-mixed design ANOVA (consisting of within and between group factors). The ANOVA $(\mathrm{F}[29,19]=92.6012, P<0.001)$ showed that there was a significant effect. We thus compared both within and between group sessions. We first compared the within group responses. In the sham control group (Fig. 4A) we found a significant difference between the number of attempted pneumostome openings in Session 6 (the savings-test session) compared to Session $1(P<0.01)$. We next compared the response in the CC with Session 1 and found

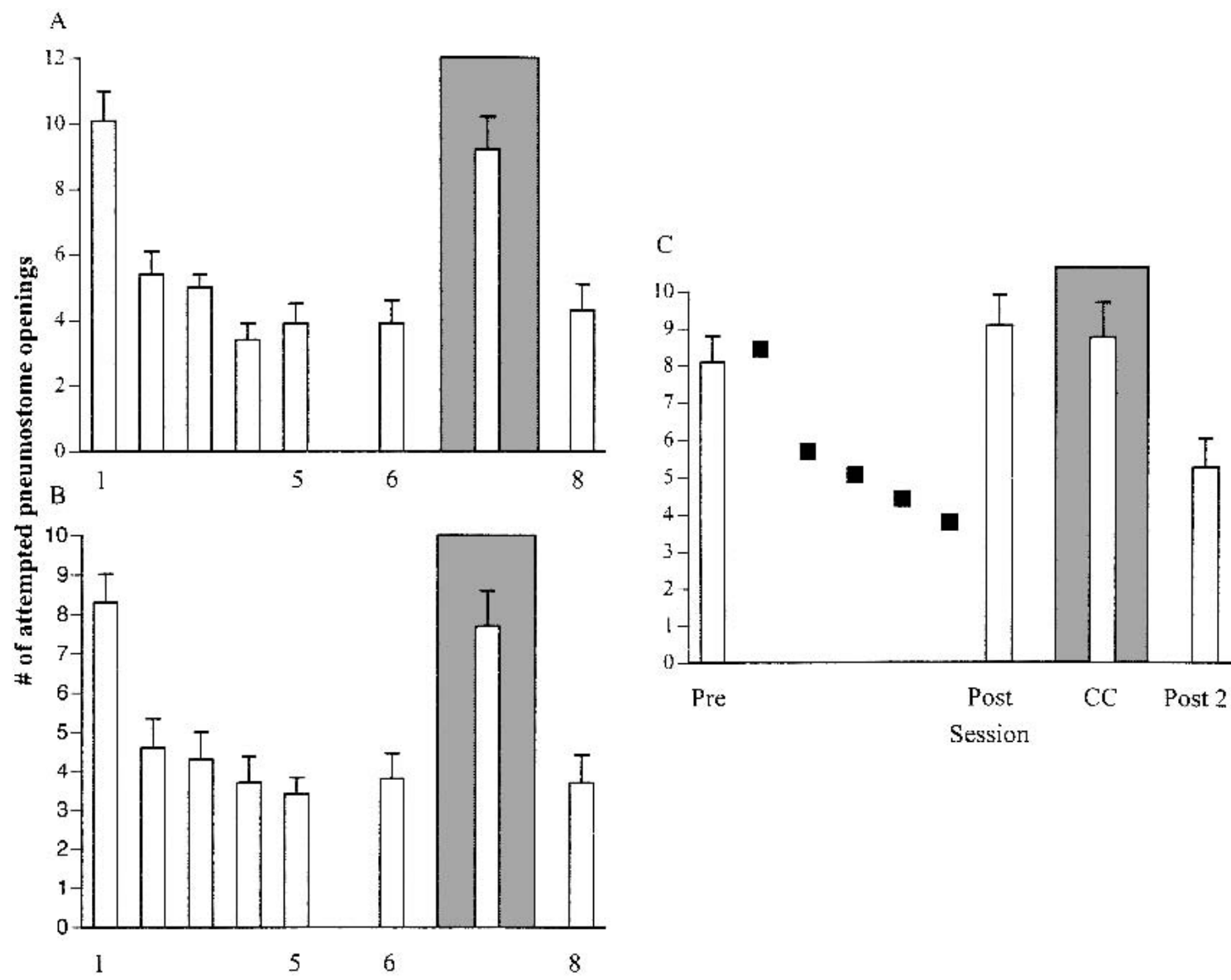

Figure 4 Associative learning in a regenerated nervous system demonstrated by a different testing procedure. The operant conditioning procedure of two 30-min. training sessions for $2.5 \mathrm{~d}$ followed by a savings-test session 1 wk later was imposed on two cohorts of snails; a sham-operated cohort $(A)$ and a functionally regenerated group $(B)$. A third cohort of functionally regenerated snails received the yoked control No. 1 procedure $(C$. In this yoked procedure (procedure No. 1), snails were first tested (Pre) and then on the next days received the yoked-training procedure (filled squares). As can be seen in $A$ and $B$, there was learning and memory in both of the operantly conditioned groups. In the yoked control cohort there was no significant difference in the number of attempted openings in the pre- vs. the posttraining session. Furthermore, the number of attempted openings in the posttraining session of the yoked control snails was significantly greater than the number of attempted pneumostome openings in the savings-test session (Session 6) of $A$ and $B$. As a further control, each of the cohorts was challenged with a CC. Notice that in the operantly conditioned cohorts $(A$ and $B)$, there was a significant difference in the number of attempted pneumostome openings in CC compared to Session 6, which was not the case with the yoked control snails. Finally, when all three cohorts were again tested (Session 8 for $A$ and $B$ and Post 2 for $C$ ) with the standard context test, there was no significant difference in the number of attempted pneumostome openings in this test compared to the savings test (Session 6$)$ in the operantly conditioned cohorts ( $A$ and $B$ ). There was however, a significant difference in the number of attempted pneumostome openings in Session 8 compared to the postsession in the yoked control group. As this postsession 2 was given $2 \mathrm{~h}$ after the first postsession test, this may indicate that these snails are now forming an association between pneumostome openings and the contingent presentation of the tactile stimulus.

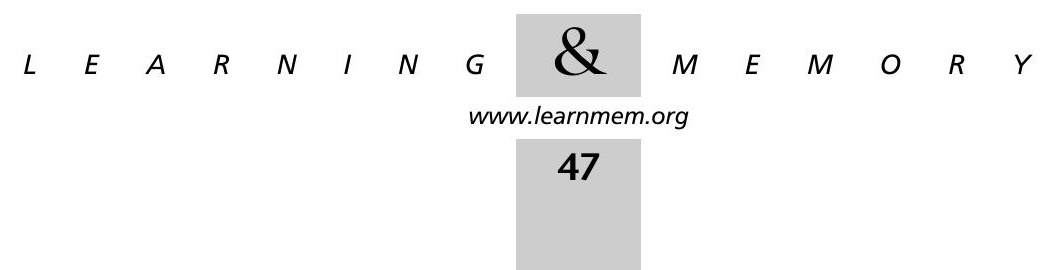


that they were not significantly different $(P>0.05)$. Comparing the response in CC with the response in Session 6 , we found a significant difference $(P<0.01)$ as we did when we compared the response in Session 8 with CC $(P<0.01)$. The interpolation of the CC (Session 7) did not have an effect on the memory, as Session 6 was not significantly different from Session $8(P>0.05)$. When we made similar within-group comparisons in the regenerated conditioned group (Fig. 4B), we found the same interactions. That is, there was a significant difference $(P<0.01)$ between Session 1 and Session 6 (the savings-test session), no significant difference $(P>0.05)$ between the CC and Session 1, a significant difference $(P<0.01)$ between Session 6 and CC, and no significant difference $(P>0.05)$ between Session 6 and Session 8. We next made within-group comparisons in the yoked control group (Fig. 4C). We found that there was no significant difference $(P>0.05)$ between the response in the pretraining session and the posttraining session. Further, there was no difference in the response between the CC and the pre- or postsession $(P>0.05$ in both comparisons). Finally, there was a significant difference between the response in postsession 2 compared to the response in the initial postsession, as was the response in postsession 2 compared to CC, and was the case when postsession 2 was compared to the presession $(P<0.01$ for each separate comparison).

Performing between-group comparisons on these data revealed the following: (1) There was no statistical difference in the response in Session 1 between the sham (Fig. 4A) and regenerated conditioned group (Fig. 4B). As well, there was no statistical difference between Session 1 in the sham group and the presession in the yoked control group (Fig. 4C); nor was there a difference between Session 1 in the regenerated conditioned group and the yoked control group ( $P>0.05$ for all comparisons). (2) There was no statistical difference $(P>0.05)$ between the savings-test session (Session 6 ) in the sham and the regenerated conditioned group. (3) There was a significant difference between Session 6 in the sham group compared to the postsession in the yoked control group; Session 6 in the regenerated operant group was also significantly different from the postsession in the yoked control group $(P<0.01$ in both comparisons). (4) There was no statistical difference in the response in CC between the sham (Fig. 4A) and regenerated conditioned group (Fig. 4B). As well, there was no statistical difference between $\mathrm{CC}$ in the sham group and $\mathrm{CC}$ in the yoked control group (Fig. 4C); nor was there a difference between $\mathrm{CC}$ in the regenerated conditioned group and CC in the yoked control group $(P>0.05$ for all comparisons). (5) A comparison of the responses in the session following the $\mathrm{CC}$ challenge revealed that there was no statistical difference $(P>0.05)$ between Session 8 in the sham group and Session 8 in the regenerated conditioned group. However, there was a statistically significant differ- ence $(P<0.01)$ between Session 8 in the sham group and the post- 2 session in the yoked group and a statistical difference between Session 8 in the regenerated conditioned group and the post- 2 session in the yoked group $(P<0.05)$; indicating that while learning and memory may have occurred in the yoked group between the first and second postsessions, it was not yet as robust as that in either the sham or operant group.

Thus, snails that receive a traumatic insult and that undergo functional regeneration are capable of learning, forming long-lasting memory, and also have the capacity to differentiate a CC.

\section{The Persistence of Memory Following Nerve Crush and Subsequent Regeneration}

We next determined whether LTM could survive the trauma of the connective crush and the subsequent regeneration process. Again, we used two different indices of memory (a significant decrease in aerial respiratory behavior in the posttraining hypoxic challenge [Fig. 5] and a significant de-

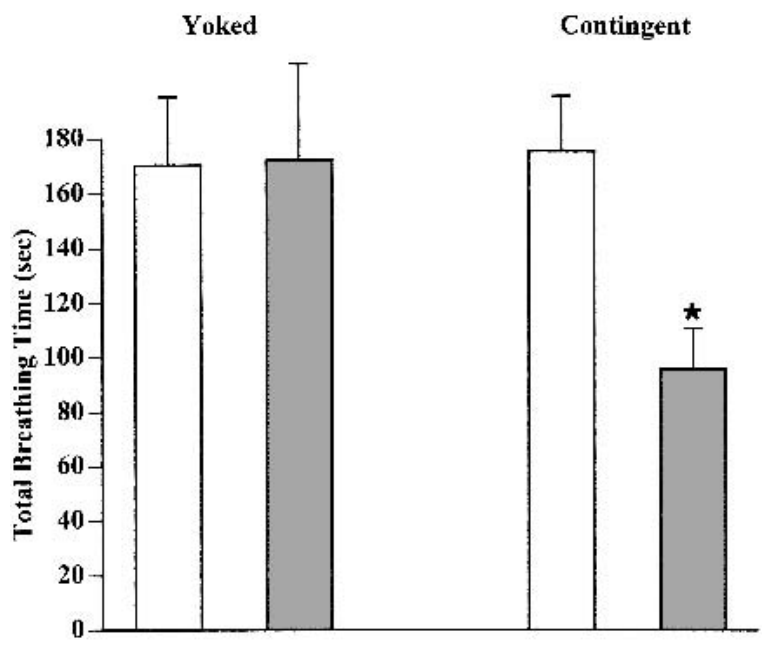

Figure 5 Memory as demonstrated by a posttraining hypoxic challenge survives axotomy and the regeneration process. All snails $(N=30)$ were given a 30-min hypoxic challenge and their total breathing time tabulated (the pretraining test, Pre). They were then randomly assigned to either the yoked or contingent training cohort. The contingent group (seven training sessions over a 10-d period) received a tactile stimulus to their pneumostome every time they attempted to open their pneumostome. Following Session 7, their right pleural-parietal connective was crushed. Ten days later, they received the posttraining hypoxic challenge (Post). The yoked group received a tactile stimulus to their pneumostome not when they opened their pneumostome, but when the snail which they were yoked to attempted to open its pneumostome. These snails received seven yoked control training sessions. Following Session 7, their right pleural-parietal connective was crushed and $10 \mathrm{~d}$ later they received the posttraining hypoxic challenge. There was no significant difference in the total breathing time (pre- vs. posthypoxic challenge) in the yoked control group. In the contingent (i.e., operant conditioning cohort) there was a significant decrease in total breathing time in the posttraining hypoxic challenge.

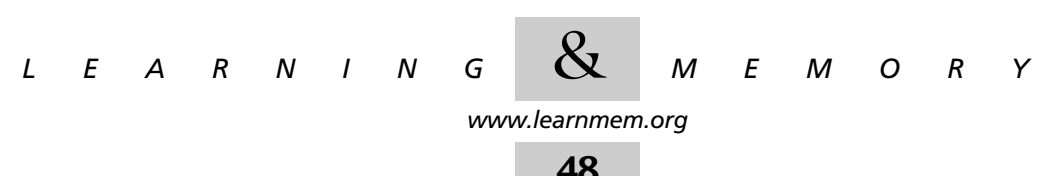


crease in the number of attempted pneumostome openings in the savings test [Fig. 6]); the two yoked control procedures; as well as a change-of-context control, to assure ourselves that LTM could survive regeneration.

Using a similar strategy as in Figure 3, we determined whether we were able to show that LTM survives axotomy and the subsequent regeneration process by comparing the breathing behavior in a 30-min hypoxic challenge (i.e., total breathing time; no reinforcing stimuli delivered) before and after operant conditioning (and of course, the nerve crush and regeneration process, Fig. 5). A group of snails $(\mathrm{N}=30)$ were first given a 30-min hypoxic challenge during which
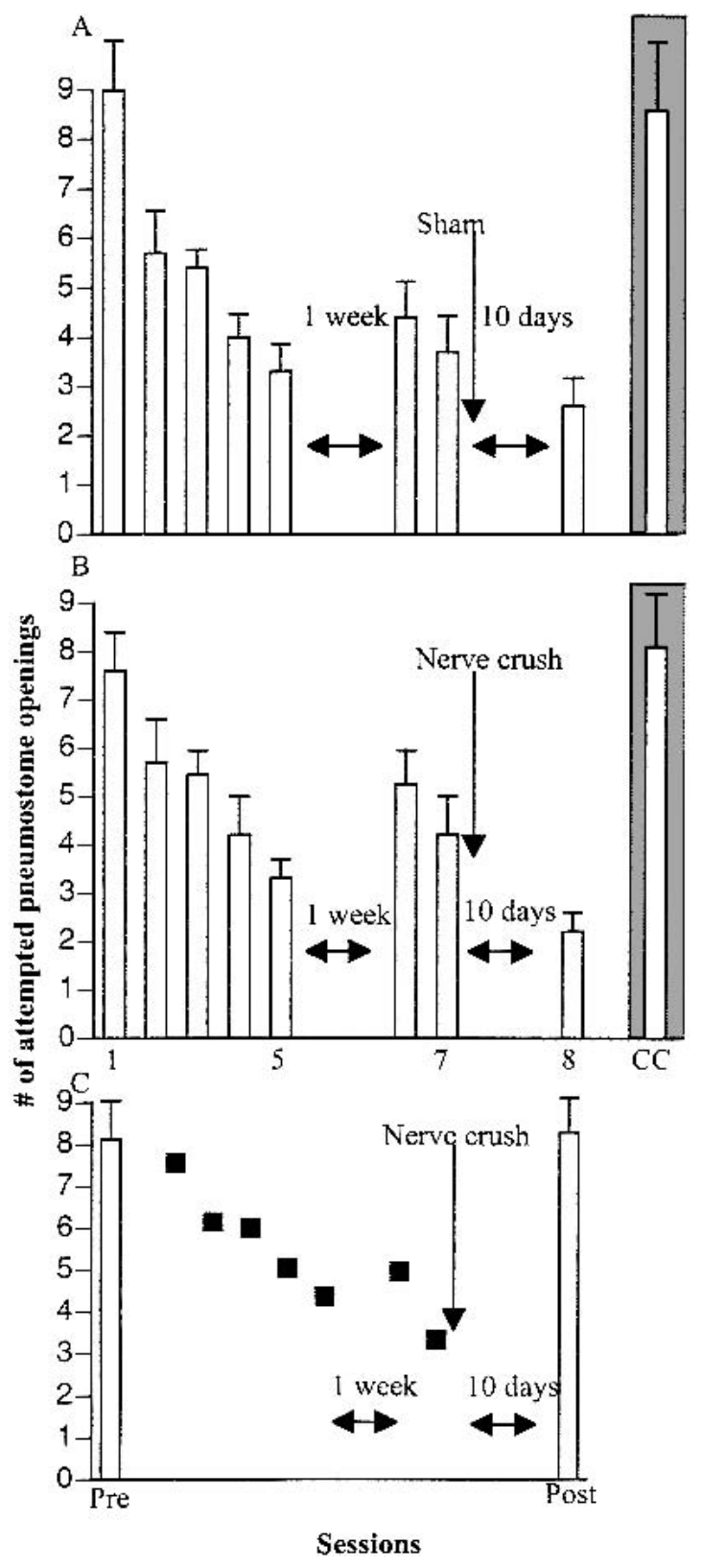

time their aerial respiratory behavior was assessed. These snails were then randomly divided into a yoked-control and an operantly conditioned group. Each group then received the seven training sessions (one group received the contingent procedure while the other received the yoked procedure) over a 10-day period followed by the nerve crush. This particular training procedure results in an LTM that persists for at least $2 \mathrm{wk}$ (Lukowiak et al. 1998). Ten days after the nerve crush, we again observed their respiratory behavior in a 30-min hypoxic challenge (i.e., the posttraining session). Following the indicated training procedure (yoked or contingent training) a one-way repeated measures ANOVA was performed on these data testing both a within-groups factor (i.e., pre vs. post) and a betweengroup factor. The ANOVA $(\mathrm{F}[11,3]=2.893, P<0.05)$ showed that there was a significant effect and thus we determined which (both within and between groups) sessions were significantly different from each other. We first determined the within-group differences between the pre- and postbreathing observation periods. There was no significant difference between the total breathing time (i.e., pre vs. post $)$ in the yoked control group $(P<0.05)$. There was, however, a significant difference in the total breathing time (pre vs. post) in the operantly conditioned (contingent) group $(P<0.01)$. Next we made between-group comparisons and found that there was not a significant difference in total breathing time in the preobservation period between the two groups $(P>0.05)$. However, there was a significant difference $(P<0.01)$ between the total breathing times in the posttraining observation period between the two groups. Thus, using the criterion of a significant change in

Figure 6 Long-term memory (LTM) survives the regeneration process. A cohort of snails received the operant conditioning training procedure of two 30-min. training sessions for $2.5 \mathrm{~d}$, followed by a further two sessions $1 \mathrm{wk}$ later. Following the last training session (Session 7), the right pedal-parietal connective was crushed in 20 of these snails $(B)$; the other 10 snails were sham-operated $(A)$. All 30 snails were capable of opening their pneumostome $10 \mathrm{~d}$ later and were given the savings test (Session 8). One hour following this test, both groups were given the change-of-context test (CC). In $C$, a yoked-procedure No. 1 control (as described in Methods and Fig. 4) was performed. After Session 7, the right pedal-parietal connective was crushed. Ten days later, these snails received the posttest session. The number of attempted openings in the posttraining session of the yoked control snails was significantly greater than the number of attempted pneumostome openings in the savings-test session (Session 8 ) of $A$ and $B$. In $A$ and $B$, the number of attempted pneumostome openings in the CC was significantly greater than the number in the savings-test session, and was not different from the number in Session 1 indicating that these snails were still capable of performing aerial respiratory behavior. In the yoked control cohort $(C)$, we did not perform a CC following the posttest because there was no difference in the number of attempted pneumostome in that session compared to the pretest session. Thus, there was no need to further demonstrate that aerial respiratory behavior was possible. Thus, memory survives axotomy and the regeneration process.

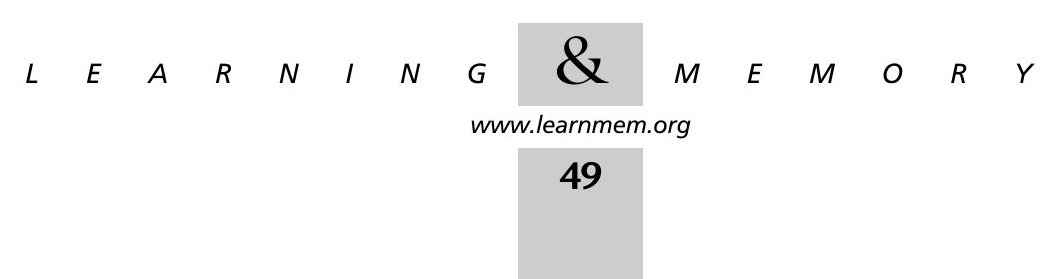


total breathing time (a decrease) we conclude that LTM of associative learning survives the regeneration process.

In the second series of experiments (similar to Fig. 4), we operantly conditioned a large group of snails $(\mathrm{N}=30$; and $\mathrm{N}=10$ for a yoked-procedure No. 1 control) using the training procedure described above that results in an LTM with a duration of $2 \mathrm{wk}$ (Fig. 6). One hour following the last training session, the snails were randomly divided into different cohorts of sham-operated (Fig. 6A; $\mathrm{N}=10$ ) and connective-crush groups (Fig. 6B; $N=20 ; \mathrm{N}=10$ for the yoked-procedure No. 1 control, Fig. 6C). We then tested all snails $10 \mathrm{~d}$ later. In this test session, all snails (including the yoked controls) received a tactile stimulus to their pneumostome when they attempted to open it. In the sham and crushed conditioned group (Fig. 6A,B) a CC was also presented to the snails following the savings-test session (Session 8).

A single-mixed design ANOVA $(\mathrm{F}[39,19]=84.0957$, $P<0.001)$ showed that there was a significant effect. Performing a similar analysis of the data as in Figure 4, we first compared within-group differences and then compared between-group differences. In the sham control group (Fig. 6A) we found a significant difference between the number of attempted pneumostome openings in Session 7 compared to Session $1(P<0.01)$. There was also a significant difference in the savings-test session given $10 \mathrm{~d}$ later (Session 8$)$ and Session $1(P<0.01)$. There was no statistically significant difference between the response in Session 7 vs. Session $8(P>0.05)$. We next compared the response in the CC with Session 1 and found that they were not significantly different $(P>0.05)$. Comparing the response in CC with the response in Session 8 (the savings-test session), we found a significant difference $(P<0.01)$. To determine if memory (i.e., savings) survived the nerve crush and regeneration process, we made similar within-group comparisons in the group shown in Figure 6B. We found the same interactions. That is, there was a significant difference $(P<0.01)$ between Session 1 and Session 7. Importantly, there was also a significant difference between Session 1 and Session 8 (the savings-test session following crush and regeneration), while there was no significant difference $(P>0.05)$ between the CC and Session 1. A significant difference $(P<0.01)$ was, however, observed between Session 8 and CC. Thus, the significantly lower number of attempted pneumostome openings in Session 8 is not the result of snails being incapable of performing aerial respiration. We next made within-group comparisons in the yoked control group (Fig. 6C). We found that there was no significant difference $(P>0.05)$ between the response in the pretraining session and the posttraining session that followed nerve crush and regeneration. That is, following the yoked control procedure, axotomy and regeneration, there was not a significant difference in the number of attempted pneumostome openings between these two sessions.
We next made between-group comparisons as we did for the snails that demonstrated learning and memory following axotomy and regeneration (Fig. 4). Performing between-group comparisons on these data revealed the following: (1) There was no statistical difference in the response in Session 1 between the sham (Fig. 6A) and nervecrush group that received operant conditioning training (Fig. 6B). As well, there was no statistical difference between Session 1 in the sham group and the presession in the yoked control group (Fig. 6C); nor was there a difference between Session 1 in the nerve-crush group that received operant conditioning training and the yoked control group ( $P>0.05$ for all comparisons). (2) There was no statistical difference $(P>0.05)$ between the savings-test session (Session 8) in the sham and the nerve-crush group that received operant conditioning training. (3) There was a significant difference between Session 8 in the sham group compared to the postsession in the yoked control group; Session 8 in the nerve-crush group that received operant conditioning training was also significantly different from the postsession in the yoked control group ( $P<0.01$ in both comparisons). (4) There was no statistical difference in the response in CC between the sham (Fig. 6A) and nerve-crush group that received operant conditioning training. We did not challenge the yoked control group to a CC, as we saw no need to demonstrate that these snails were capable of responding to the hypoxic stimulus because their level of responsiveness in the posttest session was not different from the pretest session.

Together, the data in Figures 5 and 6 demonstrate that LTM survives the traumatic insult of the nerve crush and the subsequent regeneration process.

\section{DISCUSSION}

The data presented here confirm and extend the findings of Haque (1999; Z. Haque, K. Lukowiak, and N. Syed, in prep.) regarding the ability of RPeD1's primary neurite to undergo functional regeneration following nerve crush to the right pleural-parietal connective. Haque (1999) demonstrated in both intact freely moving snails using behavioral criteria and in isolated ganglionic preparations using electrophysiological and anatomical criteria that functional regeneration of RPeD1's primary neurite occurred following crush of the right pleural-parietal connective. Our data show that following the successful regeneration of RPeD1's primary neurite snails have the ability to learn and form LTM. In addition, we show that in snails that have already consolidated associative learning into LTM, axotomy and the subsequent regeneration of RPeD1's primary neurite does not abolish the LTM.

It was possible that following the crush, some other neuron took over RPeD1's functions in the CPG circuit. We believe this does not occur for the following reasons. Because snails that had their right pleural-parietal connective

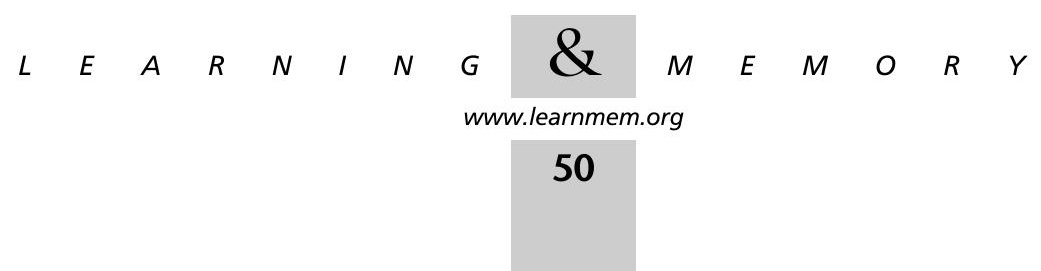


cut never regained the ability to perform aerial respiration, and because crush of this connective only transiently interrupts aerial respiratory behavior, it is unlikely that some other neuron took over the function of RPeD1. Moreover, enzymatic destruction of RPeD1 by pronase injection abolished aerial respiratory behavior for the rest of the life (at least $2 \mathrm{wk}$ ) of the snail (Haque 1999). Ten days following nerve-crush LY injections of RPeD1 show that the dye fills the neurite past the crush point into the visceral ganglia and out to the periphery. Haque (1999) has also demonstrated electrophysiologically that $\mathrm{RPeD} 1$ remade appropriate synaptic connections with the other members of the central pattern generator that control aerial respiratory behavior. Further, in isolated ganglionic preparations and in cell-culture experiments, regeneration of RPeD1's primary neurite and the reestablishment of RPeD1's synaptic connections to its follower neurons had previously been demonstrated (Benjamin and Allison 1985; Syed et al. 1990; Haque 1999). Finally, the physical removal from the CNS of one of the CPG neurons (VD4) abolishes aerial respiratory behavior (Syed et al. 1992). However, the subsequent transplantation of a VD4 from a donor animal into a VD4-less snail allows aerial respiratory behavior to be reestablished some $10 \mathrm{~d}$ later (Syed et al. 1992). Thus, we conclude that $10 \mathrm{~d}$ after crushing of the right pleural-parietal connective, functional regeneration of RPeD1 primary neurite occurs allowing functional recovery of the three-neuron network.

Using two different approaches of looking at associative learning and its memory, we showed that associative learning occurs in a regenerated nervous system and that LTM survives the regenerative process. When one tests whether learning has occurred and memory has been formed, there is always a dilemma that must be faced (Wagner and Rescorla 1972; Mackintosh 1974). If the reinforcing stimulus is applied in the test session for memory, then this should best be described as a savings test (Wagner and Rescorla 1972), as it's really just another training session. An obvious way around this is to have a memory test in which the reinforcing stimulus is not applied. However, this experimental strategy creates other problems. First, this form of memory test can also be considered an extinction session that may result in a within-session inhibition as a result of the lack of reinforcement. As well, what does one compare the memory test session with? If a pretraining session is performed in which a reinforcing stimulus is not applied, this might result in the phenomenon of latent inhibition and affect the conditioning process (Wagner and Rescorla 1972). We therefore tested for learning and LTM using both methods and obtained consistent results. Further, by using two different yoked-control procedures and the $\mathrm{CC}$, we are confident that we have shown that LTM can survive the regeneration process.

Is the savings (i.e., LTM) of the conditioned behavior encoded within the Lymnaea respiratory CPG? We believe so for the following four reasons. First, the type of memory we are studying (nondeclarative memory) is thought to reside within the neural circuit that mediates the behavior (Milner et al. 1998; Kandel and Pittenger 1999). Second, changes in the activity of CPG neurons, and the synaptic connections between the CPG neurons, have been correlated with learning and LTM (Spencer et al. 1999). Third, changes in RPeD1 activity correlated with LTM survive the dissection process and are observable in semi-intact, behaving preparations (Spencer et al. 2002). Fourth, RPeD1 is a site of LTM formation and storage (Scheibenstock et al. 2002). In those experiments, the soma of RPeD1 was ablated, leaving the surviving primary neurite intact. If performed before operant conditioning training, this procedure prevents the establishment of LTM but does not interfere with learning or the establishment of intermediate-term memory (ITM). ITM typically persists for only 2-3 h (Lukowiak et al. 2000; Scheibenstock et al. 2002). Thus, sites of the formation and storage of the LTM appear to be contained within the respiratory CPG network and as the data show, the changes that constitute LTM survive the trauma caused by axotomy and subsequent regeneration.

In the leech model system, a regenerated CNS is competent to mediate sensitization, a form of nonassociative learning (Modney et al. 1997). In an analogous situation, both nonassociative and associative learning has been shown following the reorganization (cell death, birth of new neurons, reassignment of neurons to new behaviors) of the insect CNS following metamorphosis (Tully et al. 1994; Weeks and Wood 1996; Weeks et al. 1997; Armstrong et al. 1998). These changes have significant effects on behavior and the ability of insects to learn and remember (Weeks et al. 1997; Zars et al. 2000). Finally, the incorporation of new neurons in specific areas of the adult rodent CNS is required for certain forms of new learning and memory (Shors et al. 2001). Thus, our finding that a regenerated nervous system in Lymnaea (Fig. 3) is capable of mediating operant conditioning is not too surprising. The learning curve of these animals in which regeneration had occurred was not noticeably different than a control naive group of snails. We have not explored whether the duration of memory retention is any different in snails that have a regenerated nervous system.

Because operant conditioning of aerial respiratory behavior leads to long-lasting changes in RPeD1 activity, we were interested to determine whether or not a trained CNS was still capable of regeneration, and if regeneration occurred, would the memory still be encoded? It was uncertain whether functional regeneration could occur because of the significant changes induced in RPeD1 by learning and its consolidation into LTM (Spencer et al. 1999, 2002). These specific learning-induced changes, a significant decrease in spontaneous activity, and inability to elicit rhythmogenesis in the CPG circuit, might have altered RPeD1's

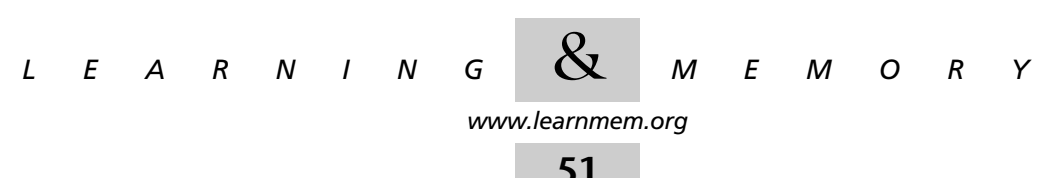


ability to reestablish the necessary synaptic connections for aerial respiratory behavior. However, aerial respiration did return following the crush with the same time course as in naive snails. More importantly however, LTM was robust enough to survive the powerful molecular signals induced by the traumatic crush and the subsequent regeneration (Figs. 5, 6). That the significantly reduced response in the savings-test session was LTM and not trauma-induced unresponsiveness was shown by both the yoked control data and the CC data. Naive functionally regenerated snails subjected to either of the two-yoked control procedures did not exhibit the same changes in aerial respiratory behavior, as did snails subjected to the operant conditioning procedure. Snails trained with either of the yoked control procedures before the nerve crush did not show any significant change in responsiveness following functional regeneration. Thus, the significant changes that were seen in aerial respiratory behavior in the operant conditioning groups are the result of associative learning and its consolidation into memory by the snails. Previously, Sahley's group demonstrated that a form of nonassociative learning, sensitization, persisted following regeneration of neurites of specific neurons in the leech (Modney et al. 1997). Here, we have shown that LTM of associative learning also survives the regeneration process. LTM also survives the process of metamorphosis (Tully et al. 1994; Ray 1999). However, whether or not the specific neurons that encode the memory (e.g., Kenyon cells of the mushroom bodies) are altered during the process of metamorphosis is not clear (Armstrong et al. 1998).

In molluscan preparations, there are a number of similarities between the cellular events underlying learning and its consolidation into LTM, axotomy, and functional regeneration. Altered gene activity and new protein synthesis are required both for memory consolidation (Milner et al. 1998), neurite outgrowth, and the reforming of synaptic connections (Feng et al. 1997; Woodin et al. 1999). Similar second-messenger cascades are also utilized to elicit gene activity in both memory consolidation (Carew and Sutton 2001) and regeneration (Feng et al. 1997; Zhang and Ambron 2000). In addition, many of the changes in neuronal activity correlated with learned behavior and LTM (e.g., long-term sensitization in Aplysia) are similar to the longterm changes brought about by axotomy and functional regeneration in Aplysia (Walters et al.1991; Ambron et al. 1996). While there are similarities between learning, memory, and functional regeneration, it is still not clear how the changes that encode LTM survive the molecular events induced by axotomy and the subsequent powerful molecular activities that subserve functional regeneration (i.e., neurite outgrowth and the successful reestablishment of synapses). How a neuron keeps track of each similar second messenger cascade signal, and which gene is to be turned on or off, is a complex cell-biology question. How- ever, researchers making use of a specific gene (e.g., the encoding BDNF) have shown how different types of neuronal stimuli can activate distinct transcriptional responses (West et al. 2001). Whether such mechanisms underlie the ability of LTM to survive functional regeneration remains to be determined.

\section{MATERIALS AND METHODS}

\section{Associative Training Procedure}

Associative learning and LTM (i.e., "savings") were produced in Lymnaea as described previously (Lukowiak et al. 1996, 2000; Spencer et al. 1999). Briefly, freely moving adult Lymnaea were placed in hypoxic pond water (bubbled with $100 \% \mathrm{~N}_{2}$ for $20 \mathrm{~min}$ ) to increase their aerial respiratory drive. They were first given a 10-min acclimatization period during which the snails were allowed to perform aerial respiration. At the end of this period they entered the 30-min training session. During the training session, the snails received a tactile stimulus (reinforcing stimulus) to the pneumostome area (the respiratory orifice) each time the snail attempted to open its pneumostome. The tactile stimulus resulted in closure of the pneumostome and the snail did not retract inside its shell. Most snails continued to remain at the surface. Thus the animals learned not to perform aerial respiration in an environment where the probability of aerial respiration is high. The snails received five training sessions over a period of $2.5 \mathrm{~d}$ (two sessions a day, with at least a 1-h interval between sessions) and a savings-test session was administered $1 \mathrm{wk}$ later to determine whether LTM was present. Data obtained for these naive, sham operated snails (see below) are shown in Figure 3A. For the experiments on naive snails following regeneration (Fig. 3B) the same training and testing procedure was used. In experiments described for operantly conditioned animals before the sham control or nerve crush (Fig. 5) these snails received two further training sessions before the nerve crush or sham control. Thus one week after the fifth training session, they received two further 30-min operant conditioning training sessions separated by at least $1 \mathrm{~h}$. This procedure results in a savings that persists for at least a 2-wk period (Lukowiak et al. 1998, 2000). Note that in the savings-test session (i.e., Session 6 for Fig. 3 and Session 8 for Fig. 5) the snail continues to receive a tactile stimulus to the pneumostome as it attempts to open it just as it does in the previous training sessions.

We also tested whether LTM was formed in a different manner. As we have previously reported (Lukowiak et al. 1996), we measured the aerial respiratory response to a hypoxic challenge (a 30-min session in hypoxic pond-water) before (pretraining) and after (posttraining) operant conditioning training. We measured the total time spent breathing during each challenge session. In these challenge sessions a tactile stimulus is not delivered to the pneumostome when the snail opens its pneumostome to perform aerial respiration. We conclude that associative learning occurs if there is significantly less breathing time in the posttraining session compared to the pretraining hypoxic challenge session. Increasing the time interval of the posttraining session from the last training session determines the persistence of memory. Of course, to conclude that the change in respiratory behavior is associative a yoked control procedure must also be performed (see below). In the yoked control procedure we would expect that there should be no significant difference in breathing between the pre- and posttraining challenge sessions, if those differences are because of associative processes. These assumptions will be statistically tested, in

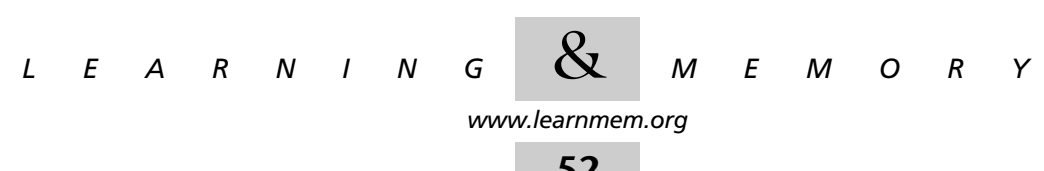


part, using a single ANOVA with two factors: a between-group factor and a repeated-measures factor (see below).

\section{Yoked Control Procedures}

Two different yoked control procedures were used in this study. The results from both show that the savings seen with the operant training procedure were the result of associative processes and not the result of application of the reinforcing stimuli to the pneumostome.

In the first modified yoked control procedure, the snails (yoked procedure No. 1; see Lukowiak et al. 2000 and Haney and Lukowiak 2001 for previous studies using this yoked control procedure) were subjected to a single 30-min training session $1 \mathrm{~d}$ before the yoking (i.e., the pretest). In this pretest every time the snail attempts to open its pneumostome it receives a tactile stimulus to its pneumostome. However, as has been previously reported, a single 30-min session does not result in LTM (Lukowiak et al. 2000). On the following days, these snails received a tactile stimulus to their pneumostome area that was not contingent upon opening their pneumostome, rather they received the tactile stimulus when the snail to which it was yoked opened its pneumostome in the operant conditioning procedure. Following yoked training, these yoked-procedure No. 1 snails then were tested in a 30-min. training procedure in which they again received a tactile stimulus every time they attempted to open their pneumostome (i.e., the posttest). We then compared the number of attempted openings in the pretest with the posttest. The number of attempted openings in the posttest was also compared to the number of attempted openings in the initial training session (Session 1) and the savings-test session in the operant conditioning group.

The second yoked control procedure (yoked procedure No. 2 ) is a more typical one. In this procedure, aerial respiratory behavior was first observed in hypoxic conditions (total breathing time and the number of pneumostome openings were recorded [i.e., the pretest]). That is, snails were allowed to perform aerial respiration without receiving any tactile stimuli. On the next day, these snails received a tactile stimulus to their pneumostome area that was not contingent upon opening their own pneumostome, rather they received the tactile stimulus when the snail to which they were yoked to opened its pneumostome in the operant conditioning procedure. We again observed their aerial respiratory behavior in hypoxic conditions (i.e., the posttraining test, no tactile stimuli were delivered) just as we did before the snails received any tactile stimuli. The exact same pre- and posttest breathing observations were performed on snails receiving operant conditioning training, and on a naive group of snails that received no tactile stimuli over the same time period. We then compared the differences between the pre- and posttraining test observations in the three groups.

\section{The Different Context Test}

Associative learning and LTM in Lymnaea is context dependent (Haney and Lukowiak 2001). That is, if snails are trained in the one context when tested in a different context, they behave as naive snails. Two contexts were used here, the standard and the foododorant context. The standard context refers to a procedure in which $\mathrm{N}_{2}$ is bubbled through the test beaker to create the hypoxic environment, whilst the food odorant context is created by first bubbling the $\mathrm{N}_{2}$ through a flask of cut-up carrots before being bubbled through the test beaker. This $\mathrm{CC}$ will serve as a control for unresponsiveness. Full details of context specific learning and memory are given in Haney and Lukowiak (2001).

\section{Surgery}

Prior to surgery, snails were anesthetized by injecting $50 \mathrm{mM}$ magnesium chloride (1-3 mL) directly into the foot to paralyze the foot musculature. The animal was then placed on a dissection tray with its foot facing downward. The tentacles were pinned down and the shell retracted. A dorsal midline incision was made to expose the central ring ganglia. Using a fine, fire-polished glass pipette, the central ring ganglia were exposed and fine forceps used to crush the axon of RPeD1 (and other neurons), traversing between the right pleural and parietal ganglia (i.e., the right pleural-parietal connective; see Fig. 1). In sham-operated animals, a skin incision was made but no nerve or connective was crushed. A second control group was also used. In this group, the right pleural-parietal connective was cut. All animals were then returned to a well-aerated tank and allowed to recover for $1 \mathrm{~d}$ before determining if they could perform aerial respiratory behavior. No suture was necessary to close the incision in any of the three groups.

To determine if a regenerated nervous system was capable of mediating associative learning and LTM, the operant conditioning procedure described above was used on previously untrained snails that had (1) their right pleural-parietal connective crushed and (2) performed aerial respiratory behavior $10 \mathrm{~d}$ after surgery (i.e., had undergone functional regeneration).

To determine if LTM (i.e., savings) survived axotomy and the subsequent regeneration process, snails were first subjected to the operant conditioning training and $1 \mathrm{~h}$ after the last training session (Session 7) the right pleural-parietal connective was crushed. Ten days later, the snails received a savings-test session (i.e., Session 8). These snails were also subjected to a different context test (i.e., Session 9) to demonstrate that aerial respiratory behavior was still possible. However, in the yoked control experiments described in Figure $6 \mathrm{C}$, we did not perform a CC challenge following the posttest because there was no difference in the number of attempted pneumostome in that session compared to the pretest session. Thus, there was no need to further demonstrate that aerial respiratory behavior was possible.

\section{Lucifer Yellow Fills}

In pilot experiments, LY fills of RPeD1 were performed $1 \mathrm{~d}$ after the nerve crush to the right pleural-parietal connective to demonstrate the effectiveness of the crush procedure. Pilot experiments showed that it took $10 \mathrm{~d}$ for aerial respiratory behavior to be reestablished following the crush. To demonstrate that regeneration of RPeD1's axon had occurred, LY fills of RPeD1 were performed on randomly picked snails 1 and $10 \mathrm{~d}$ after the crush. We followed the procedure for LY fills in in vivo preparations as described previously for Lymnaea (Syed et al. 1992). When tested with a hypoxic challenge $1 \mathrm{~d}$ after the crush, snails did not perform aerial respiration; whilst aerial respiration was performed in the snails examined $10 \mathrm{~d}$ after the nerve crush

\section{Statistics}

To determine whether breathing behavior (total breathing time) changed as a result of operant conditioning training (Figs. 3, 5), we employed a one-way, repeated-measures ANOVA: testing both a within-groups factor (i.e., pre vs. post) and a between-group factor (i.e., naive, contingent, yoked [Zar 1999]). If the ANOVA is signifi-

\section{$\begin{array}{lllllllllllllll}\text { www.learnmem.org } & & & & & & & & & & & & \end{array}$}


cant $(P<0.05)$, a post-hoc Fisher's LSD t-test was performed to show which individual sessions were significantly different.

To determine whether the number of attempted pneumostome openings are significantly altered as a result of operant conditioning in sham controls and regenerated and yoked control snails (Figs. 4, 6), we used a statistical design with one betweengroup factor (i.e., sham-control operantly conditioned, regenerated operantly conditioned, and regenerated yoked control) and two within-group factors (i.e., Factor II: Sessions 1, 6, 7, 8; and Factor III context effects). If the ANOVA is significant $(P<0.05)$, a post-hoc Fisher's LSD t-test was performed to show which individual sessions were significantly different. Differences were considered to be significant if $P<0.05$.

All behavioral observations were performed blind. The researcher performing behavioral observations was unaware of the surgical procedures performed on the animals, and the investigator performing the surgery was unaware whether the animal had been trained, was a yoked control, or was naive.

\section{ACKNOWLEDGMENTS}

This work is supported by CIHR. G. Spencer is a Parker B. Francis Fellow in Pulmonary Research.

The publication costs of this article were defrayed in part by payment of page charges. This article must therefore be hereby marked "advertisement" in accordance with 18 USC section 1734 solely to indicate this fact.

\section{REFERENCES}

Ambron, R., Zhang, X.-P., Gunstream, J., Povelones, M., and Walters, E. 1996. Intrinsic injury signals enhance growth, survival, and excitability of Aplysia neurons. J. Neurosci. 16: 7469 -7477.

Armstrong, J., de Belle, J., Wang, Z., and Kaiser, K. 1998. Metamorphosis of the mushroom bodies; Large-scale rearrangements of the neural substrates for associative learning and memory in Drosophila. Learn. Mem. 5: 102-114.

Benjamin, P. and Allison, P. 1985. Regeneration of excitatory, inhibitory and biphasic synaptic connections made by a snail giant interneuron. Proc. R. Soc. Lond. 226: 159-176.

Carew, T. and Sutton, M. 2001. Molecular stepping stones in memory consolidation. Nat. Neurosci. 4: 769-771.

Feng, Z.-P., Klumperman, J., Lukowiak, K., and Syed, N. 1997. In vitro synaptogenesis between the somata of identified Lymnaea neurons requires protein synthesis but not extrinsic growth factors or substrate adhesion molecules. J. Neurosci. 17: 7839-7849.

Haney, J. and Lukowiak, K. 2001. Context learning and the effect of context on memory retrieval in Lymnaea. Learn. Mem. 8: 35-43.

Haque, Z. 1999. Role of the dopaminergic neuron (RPeD1) in the control of respiratory behaviour in Lymnaea stagnalis. MSc Thesis, University of Calgary.

Hermann P. and Bulloch, A. 1998. Developmental plasticity of respiratory behavior in Lymnaea. Behav. Neurosci. 112: 656-667.

Kandel, E. and Pittenger, C. 1999. The past, the future and the biology of memory storage. Philos. Trans. R. Soc. Lond. B. Biol. Sci. 354: 2027-2052.

Lukowiak, K., Ringseis, E., Spencer, G., Wildering, W., and Syed, N. 1996. Operant conditioning of aerial respiratory behaviour in Lymnaea stagnalis. J. Exp. Biol. 199: 683-691.

Lukowiak, K., Cotter, R., Westly, J., Ringseis, E., Spencer, G., and Syed, N. 1998. Long-term memory of an operantly conditioned respiratory behaviour in Lymnaea stagnalis. J. Exp. Biol. 201: 877-882.

Lukowiak, K., Adatia, N., Krygier, D., and Syed, N. 2000. Operant conditioning in Lymnaea: Evidence for intermediate- and long-term memory. Learn. Mem. 7: 140-150.
Mackintosh, N. 1974. The Psychology of Animal Learning. Academic Press, New York, NY.

Milner, B., Squire, L., and Kandel, E. 1998. Cognitive neuroscience and the study of memory. Neuron 20: 445-468.

Modney, B., Sahley, C., and Muller, K. 1997. Regeneration of a central synapse restores nonassociative learning. J. Neurosci. 17: 6478-6482

Ray, S. 1999. Survival of olfactory memory through metamorphosis in the fly Musca domestica. Neurosci. Lett. 259: 37-40.

Sangha, S., McComb, C., Scheibenstock, A., Johannes, C., and Lukowiak, K. 2002. The effects of continuous vs. partial reinforcement schedules on associative learning, memory and extinction in Lymnaea. J. Exp. Biol. 205: 1171-1178.

Scheibenstock, A., Krygier, D., Haque, Z., Syed, N., and Lukowiak, K. 2002. The soma of RPeD1 must be present for long-term memory formation of associative learning and memory. J. Neurophysiol. 88: 1584-1591.

Shors, T., Miesegaes, G., Beylin, A., Zhao, M., Rydel, T., and Gould, E. 2001. Neurogenesis in the adult is involved in the formation of trace memories. Nature 410: 372-375.

Smyth, K., Sangha, S., and Lukowiak, K. 2002. Gone but not forgotten: The lingering effects of intermediate term memory on the persistence of LTM. J. Exp. Biol. 205: 131-140.

Spencer, G.E., Syed, N.I., and Lukowiak, K. 1999. Neural changes after operant conditioning of the aerial respiratory behavior in Lymnaea stagnalis. J. Neurosci. 19: 1836-1843.

Spencer, G.E., Kazmi, M.H., Syed, N.I., and Lukowiak, K. 2002. Change in activity of a central pattern generator neuron following the reinforcement of an operantly conditioned behavior in Lymnaea. J. Neurophysiol. 88: 1915-1923.

Syed, N. and Winlow, W. 1991. Respiratory behavior in the pond snail Lymnaea stagnalis. II Neural elements of the central pattern generator (CPG). J. Comp. Physiol. A 169: 557-568.

Syed, N.I., Bulloch, A.G.M., and Lukowiak, K. 1990. In vitro reconstruction of the respiratory central pattern generator of the mollusk Lymnaea. Science 250: 282-285.

Syed, N.I., Ridgway, R., Lukowiak, K., and Bulloch, A.G.M. 1992. Transplantation and functional regeneration of an identified respiratory interneuron in Lymnaea stagnalis. Neuron 8: 767-774.

Tully, T., Cambiazo, V., and Kruse, L. 1994. Memory through metamorphosis in normal and mutant Drosophila. J. Neurosci. 14: $68-74$.

Wagner, A. and Rescorla, R. 1972. Inhibition in pavlovian conditioning: Application of a theory. In Inbibition and learning. (eds. R. Boakes and M. Halliday), pp. 301-336. Academic Press, London, UK.

Walters, E., Alizadeh H., and Castro, E. 1991. Similar neuronal alterations induced by axonal injury and learning in Aplysia. Science 253: 797-799.

Weeks, J. and Wood, E. 1996. Short- and long-term modification of reflex function during learning and metamorphosis in Manduca. Biol. Bull. 191: 62-69.

Weeks, J., Jacobs, G., Pierce, J., Sandstrom, D., Streichert, L., Wiel, D., and Wood, E. 1997. Neural mechanisms of behavioral plasticity: Metamorphosis and learning in Manduca. Brain Behav. Evol. (Suppl.) 50: 69-80.

West, A., Chen, W., Dalva, M., Dolmetsch, R., Kornhauser, J., Shaywitz, A., Takasu, M., Tao, X., and Greenberg, M. 2001. Calcium regulation of neuronal gene expression. Proc. Nat. Acad. Sci. 98: 11024-11031.

Woodin, M., Hamakawa, T., Takasaki, M., Lukowiak, K., and Syed, N. 1999. Trophic factor-induced plasticity of synaptic connections between identified Lymnaea neurons. Learn. Mem. 6: 307-316.

Zhang, X.-P. and Ambron, R. 2000. Positive injury signals induce growth and prolong survival in Aplysia neurons. J. Neurobiol. 45: 84-94.

Zar, J.H. 1999. Biostatistical analysis, 3rd ed. Prentice Hall, Upper Saddle River, NJ.

Zars, T., Fisher, M., Schulz, R., and Heisenberg, M. 2000. Localization of a short-term memory in Drosophila. Science 288: 672-675.

Received March 28, 2002; accepted in revised form November 26, 2002.

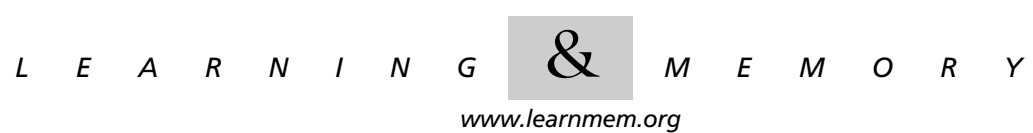




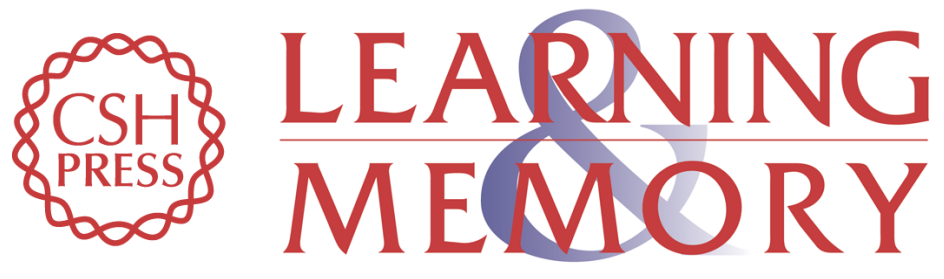

\section{Long-Term Memory Survives Nerve Injury and the Subsequent Regeneration Process}

Ken Lukowiak, Zara Haque, Gaynor Spencer, et al.

Learn. Mem. 2003, 10:

Access the most recent version at doi:10.1101/lm.48703

References This article cites 30 articles, 17 of which can be accessed free at: http://learnmem.cshlp.org/content/10/1/44.full.htmI\#ref-list-1

License

Email Alerting Receive free email alerts when new articles cite this article - sign up in the box at the Service top right corner of the article or click here. 